\title{
Activation of Muscle Fibers in Individual Motor Units Revealed by 2-Deoxyglucose-6-Phosphate
}

\author{
P. M. Nemeth, ${ }^{1}$ B. J. Norris, ${ }^{1}$ O. H. Lowry, ${ }^{2}$ D. A. Gordon, ${ }^{3}$ R. M. Enoka, ${ }^{3}$ and D. G. Stuart ${ }^{3}$ \\ Departments of 'Neurology and of Anatomy and Neurobiology, and of PPharmacology, Washington University School of \\ Medicine, St. Louis, Missouri 63110, and the ${ }^{3}$ Department of Physiology, Arizona Health Sciences Center, University of \\ Arizona, Tucson, Arizona 85724
}

\begin{abstract}
Motor units of the cat tibialis posterior muscle were selectively activated by prolonged electrical stimulation of functionally isolated motor axons in situ. During the activation, the glucose analog 2-deoxyglucose (DG) was administered systemically. Single muscle fibers were subsequently examined for accumulation of the metabolite 2-deoxyglucose6-phosphate (DG6P) by an analytical assay and for depletion of glycogen by a PAS glycogen-specific staining reaction (periodic acid Schiff; PAS). In general, levels of DG6P were 20 times greater in unstained (PAS-negative) fibers compared with stained (PAS-positive) fibers. However, some glycogen-depleted fibers, particularly in putative ischemic fascicles of the muscle, did not have elevated DG6P, suggesting that depletion of glycogen is not always a reliable indicator of fiber activation. Furthermore, the PAS-staining reaction was not necessarily indicative of quantitative glycogen levels in single fibers. Thus, this report shows that DG6P accumulation enhances the identification of motor-unit fibers selectively activated via their common motor-nerve axon. Evidence is also presented for differential glucose uptake in muscle fibers of different phenotype, thereby indicating that the DG6P measurement in muscle has broad applicability to the investigation of cellular glucose utilization.
\end{abstract}

Motoneurons, motor axons, and muscle cells are characterized by wide ranges of biochemical, morphological, and functional properties. Despite this variety, the properties of a particular muscle and its nerve are closely matched. This is evident even at the level of the motor unit, which comprises the cell body and dendrites of a motoneuron, its axon, and the muscle fibers innervated by the intramuscular branches of the axon (for reviews, see Vrbová et al., 1978; Burke, 1981; Hamm et al., 1987).

The biochemical and morphological characterization of the constituent muscle fibers of a motor unit was made possible largely by the glycogen-depletion technique (Krnjevic and Miledi, 1958; Edström and Kugelberg, 1968). This method takes advantage of the fact that active muscle fibers utilize endogenous glycogen as a substrate for energy metabolism. Following the

\footnotetext{
Received Apr. 29, 1987; revised Mar. 16, 1988; accepted Mar. 18, 1988.

We are grateful to Dr. G. A. Robinson, Mrs. P. A. Pierce, and Mr. J. M. Spielmann for technical assistance and to Dr. R. S. Wilkinson for critical reading of the manuscript. The work was supported by USPHS Grants NS 18387, NS 20762, and HL 07249 and by the Muscular Dystrophy Association.

Correspondence should be addressed to Dr. Patti M. Nemeth, Department of Neurology, Box 8111, Washington University School of Medicine, St. Louis, MO 63110.

Copyright @ 1988 Society for Neuroscience $0270-6474 / 88 / 113959-08 \$ 02.00 / 0$
}

selective activation of a single motor unit by electrical stimulation of its motoneuron, the muscle fibers of the unit are identified in cross sections stained with the glycogen-specific stain, PAS. Identification is based on the presumption that unstained (PAS-negative) fibers had been active and therefore belong to the stimulated motor unit. Recently, we have observed entire muscle fascicles composed of PAS-negative fibers or seemingly spurious glycogen depletion in isolated fibers (Nemeth et al., 1986). Neither of these occurrences were thought to be due to the selective activation of the test unit. Therefore, the adequacy of the glycogen-depletion technique to distinguish between activation- and nonactivation-induced metabolism of glycogen was suspect. Others have expressed similar concerns (McDermott et al., 1987).

Thus, despite the wide applicability of the glycogen-depletion technique, it is not without limitations. The technique does not guarantee that all motor-unit fibers will be depleted or that nonactivated fibers will be glycogen rich. One approach to this situation is to use an independent measure of muscle-fiber activation. Two processes for the utilization of carbohydrate substrates for energy metabolism are operative during muscle fiber activation: endogenous glycogen breakdown and exogenous glucosc uptakc. In this study, wc exploited the process of activationinduced glucose uptake to entice cells to take up the glucose analog, 2-deoxyglucose (DG). Muscle cells metabolize DG to an inactive product, 2-deoxyglucose-6-phosphate (DG6P), which is accumulated in the cell. Levels of DG6P can then be used as a measure of glucose uptake in single fibers. A preliminary account of these results has been published (Gordon et al., 1987).

We have found that levels of DG6P are 20 times higher in the muscle fibers belonging to a selectively activated motor unit than in control fibers, regardless of the glycogen levels of the control fibers. In addition, we observed higher basal glucose uptake in slow, as compared with fast, muscle fibers. Thus, we predict that the quantitative measurement of the DG6P accumulation will have considerable value in motor-unit identifcation, as well as in studies of glucose metabolism and energy utilization in single muscle cells.

\section{Materials and Methods}

Physiological procedures. The investigation was carried out on the tibialis posterior muscle of adult cats $(2-4 \mathrm{~kg})$ that received $5 \%$ corn syrup for $3 \mathrm{~d}$ prior to experimentation to increase the storage of glycogen in muscle. The surgical and electrophysiological procedures have been described in detail (McDonagh et al., 1980). Briefly, the animals were maintained at a deeply anesthetized, pain-free level with sodium pentobarbital during the experimental procedures, which included a laminectomy to expose the ventral roots (L6, L7, and S1), a complete limb 
Table 1. Biochemical characterization of nonactivated individual fibers of 3 types

\begin{tabular}{|c|c|c|c|c|c|}
\hline \multirow[b]{2}{*}{ Fiber type } & \multirow[b]{2}{*}{ Glycogen } & \multirow[b]{2}{*}{ DG6P } & \multicolumn{3}{|c|}{ Type determinant enzymes } \\
\hline & & & $\begin{array}{l}\text { Adenylo- } \\
\text { kinase }\end{array}$ & $\begin{array}{l}\text { Lactate } \\
\text { dehydrogenase }\end{array}$ & $\begin{array}{l}\text { Malate } \\
\text { dehydro- } \\
\text { genase }\end{array}$ \\
\hline \multicolumn{6}{|l|}{ Slow } \\
\hline 1 & 143 & 2.9 & 49 & 52 & 20 \\
\hline 2 & 139 & 15.1 & 41 & 29 & - \\
\hline 3 & 147 & 17.8 & 34 & 30 & 15 \\
\hline 4 & 186 & 9.3 & 37 & 33 & 16 \\
\hline 5 & 115 & 5.3 & 24 & 20 & 17 \\
\hline Mean \pm SD & $146 \pm 26$ & $10.1 \pm 6.3$ & $37 \pm 9$ & $33 \pm 12$ & $17 \pm 3$ \\
\hline \multicolumn{6}{|l|}{ Fast-oxidative } \\
\hline 6 & 163 & 4.2 & 119 & 187 & 10 \\
\hline 7 & 192 & 3.6 & 112 & 186 & 9 \\
\hline 8 & 186 & 1.8 & 108 & 177 & 13 \\
\hline 9 & 183 & 3.9 & - & 128 & 17 \\
\hline 10 & - & - & 92 & 165 & 21 \\
\hline 11 & - & - & - & 196 & 15 \\
\hline 12 & - & - & 115 & 200 & 12 \\
\hline Mean \pm SD & $181 \pm 13$ & $3.4 \pm 1.1$ & $109 \pm 10$ & $177 \pm 25$ & $14 \pm 4$ \\
\hline \multicolumn{6}{|l|}{ Fast-glycolytic } \\
\hline 13 & 202 & 3.2 & 126 & 182 & 3 \\
\hline 14 & 213 & 3.4 & 127 & 174 & 5 \\
\hline 15 & 199 & 2.9 & 125 & 180 & 6 \\
\hline 16 & 212 & 5.0 & 113 & 182 & 6 \\
\hline 17 & 249 & 2.5 & - & - & - \\
\hline 18 & 238 & 3.2 & - & - & - \\
\hline 19 & 215 & 2.7 & - & - & - \\
\hline Mean \pm SD & $218 \pm 19$ & $3.3 \pm 0.8$ & $123 \pm 7$ & $180 \pm 4$ & $5 \pm 1$ \\
\hline
\end{tabular}

Glycogen and DG6P concentrations are expressed in mmol $/ \mathrm{kg}$; enzyme activities are in $\mathrm{mol} / \mathrm{kg} / \mathrm{hr}$.

denervation except for the test muscle, and the subsequent data-acquisition procedures. The distal tendon of the muscle was attached to a strain gauge. Single motor axons supplying the test muscle were isolated in ventral-root filaments and activated by $0.1 \mathrm{msec}$ electrical square pulses. A multiunit neurogram was obtained from a recording electrode positioned on the nerve near the muscle. The averaged action potential extracted from the neurogram served as proof of functional, single motor-unit isolation. The motor units were characterized physiologically by measurements of axonal conduction velocity, twitch contraction time, peak tetanic force, and fatigue resistance. The motor unit was depleted of its glycogen by extending the fatigue-test stimulus regimen ( 13 pulses in $330 \mathrm{msec}$ trains, repeated once per second) for $15 \mathrm{~min}$ in fatiguesensitive units and for $60 \mathrm{~min}$ in fatigue-resistant units.

During the last $15 \mathrm{~min}$ of the glycogen-depletion procedure, DG was infused intravenously. Three $6 \mathrm{ml}$ boli of $500 \mathrm{~mm}$ DG (2-deoxy-Dglucose), dissolved in balanced glucose solution ( $28 \mathrm{~mm}$ glucose, $90 \mathrm{~mm}$ $\mathrm{NaCl}_{2}, 23 \mathrm{~mm}$ sodium gluconate, $45 \mathrm{~mm}$ sodium acetate, $3.5 \mathrm{~mm} \mathrm{KCl}$, $3.2 \mathrm{mM} \mathrm{MgCl}, \mathrm{pH} \mathrm{5.5),} \mathrm{were} \mathrm{administered} \mathrm{at} 5 \mathrm{~min}$ intervals. The DG was applied in pulses to enhance availability to the muscle fibers since it is known that plasma DG falls to about $20 \%$ of initial levels in 15 min (Sokoloff et al., 1977). Assuming the circulatory volume of cats to be about $250 \mathrm{ml}$, the blood level of DG was maintained at approximately $12 \mathrm{~mm}$ for the $15 \mathrm{~min}$ interval.

Tissue handling. Immediately after the glycogen-depletion procedure, the muscle was removed and divided into 4 or 5 blocks of about $5 \times$ $5 \times 12 \mathrm{~mm}$, with the fibers oriented longitudinally. Each block was mounted in an embedding medium, quickly frozen, and stored at $-70^{\circ} \mathrm{C}$. Later, transverse sections $16-18 \mu \mathrm{m}$ thick were cut on a cryostat microtome, taking successive sections for myosin ATPase (preincubated at pH 4.5), for PAS staining, and for analytical biochemistry. The latter sections were lyophilized for $24 \mathrm{hr}$ at $-38^{\circ} \mathrm{C}$. Fibers identified as PAS negative in the stained cross sections were located in the adjacent ly- ophilized unstained sections and dissected out for biochemical processing (for technical details, see Nemeth et al., 1986).

DG6P assay. The DG6P procedure was adopted from the method of Chi et al. (1987). The assay is based on the fact that glucose 6-phosphate dehydrogenase (G6PDH) catalyzes the oxidation by NADP+ of both glucose 6-phosphate and DG6P but at rates that differ by a factor of more than 1000. Glucose 6-phosphate is first removed with a low level of G6PDH and the NADPH formed is destroyed with acid. The DG6P is then oxidized with a much higher level of enzyme, and the resultant NADPH is measured by its fluorescence.

Muscle fiber fragments (20-50 ng dry weight) were incubated under oil in $0.5 \mu \mathrm{l}$ of $20 \mathrm{mM} \mathrm{HCl}$ for $20 \mathrm{~min}$ at $80^{\circ} \mathrm{C}$. A $0.5 \mu \mathrm{l}$ aliquot of the specific assay reagent for glucose 6-phosphate was added. It contained $100 \mathrm{~mm}$ Tris-HCl, pH 8.5 (acid : base, 30:70), 0.04\% BSA, $200 \mu \mathrm{M}$ $\mathrm{NADP}^{+}, 0.2 \mu \mathrm{g} / \mathrm{ml}$ G6PDH from Leuconostoc mesenteroides, $150 \mu \mathrm{g}$ $\mathrm{ml}$ glucose oxidase from Aspergillus niger, and $2 \mu \mathrm{g} / \mathrm{ml}$ aldose mutarotase. After $30 \mathrm{~min}$ at $25^{\circ} \mathrm{C}$, the reaction was stopped, and the NADPH formed from the glucose 6-phosphate was destroyed by adding $0.5 \mu 1$ of $0.08 \mathrm{~N} \mathrm{HCl}$ and incubating for $10 \mathrm{~min}$ at $25^{\circ} \mathrm{C}$. A $1 \mu \mathrm{l}$ volume of the specific assay reagent for DG6P was added and incubated for $30 \mathrm{~min}$ at $25^{\circ} \mathrm{C}$. This reagent contained $100 \mathrm{~mm}$ Tris-HCl, pH 8.6 (acid : base, $25: 75), 0.05 \% \mathrm{BSA}, 200 \mu \mathrm{M} \mathrm{NADP}+$, and $125 \mu \mathrm{g} / \mathrm{ml}$ baker's yeast G6PDH. Special treatment of the G6PDH was required to remove contaminating 6-phosphogluconate dehydrogenase (Chi et al., 1987).

The second reaction was stopped with $1 \mu \mathrm{l}$ of $0.25 \mathrm{~N} \mathrm{NaOH}$ and heat $\left(80^{\circ} \mathrm{C}\right.$ for $\left.20 \mathrm{~min}\right)$. A $2 \mu \mathrm{l}$ aliquot of the mixture was added to $100 \mu \mathrm{l}$ of cycling reagent in a fluorometer tube. The cycling reagent, adjusted for 40,000 cycles, contained $100 \mathrm{~mm}$ imidazole- $\mathrm{HCl}$, pH 7.4, 7.5 mM $\alpha$-ketoglutarate (monosodium salt), $5 \mathrm{~mm}$ glucose 6 -phosphate, $0.1 \%$ BSA, $100 \mu \mathrm{M}$ ADP, $25 \mathrm{~mm}$ ammonium acetate, $7.5 \mathrm{~mm} \mathrm{NaOH}, 400$ $\mu \mathrm{g} / \mathrm{ml}$ glutamate dehydrogenase, and $8 \mu \mathrm{g} / \mathrm{ml}$ G6PDH from baker's yeast. The cycling reaction was run for $1 \mathrm{hr}$ at $38^{\circ} \mathrm{C}$ and was then 


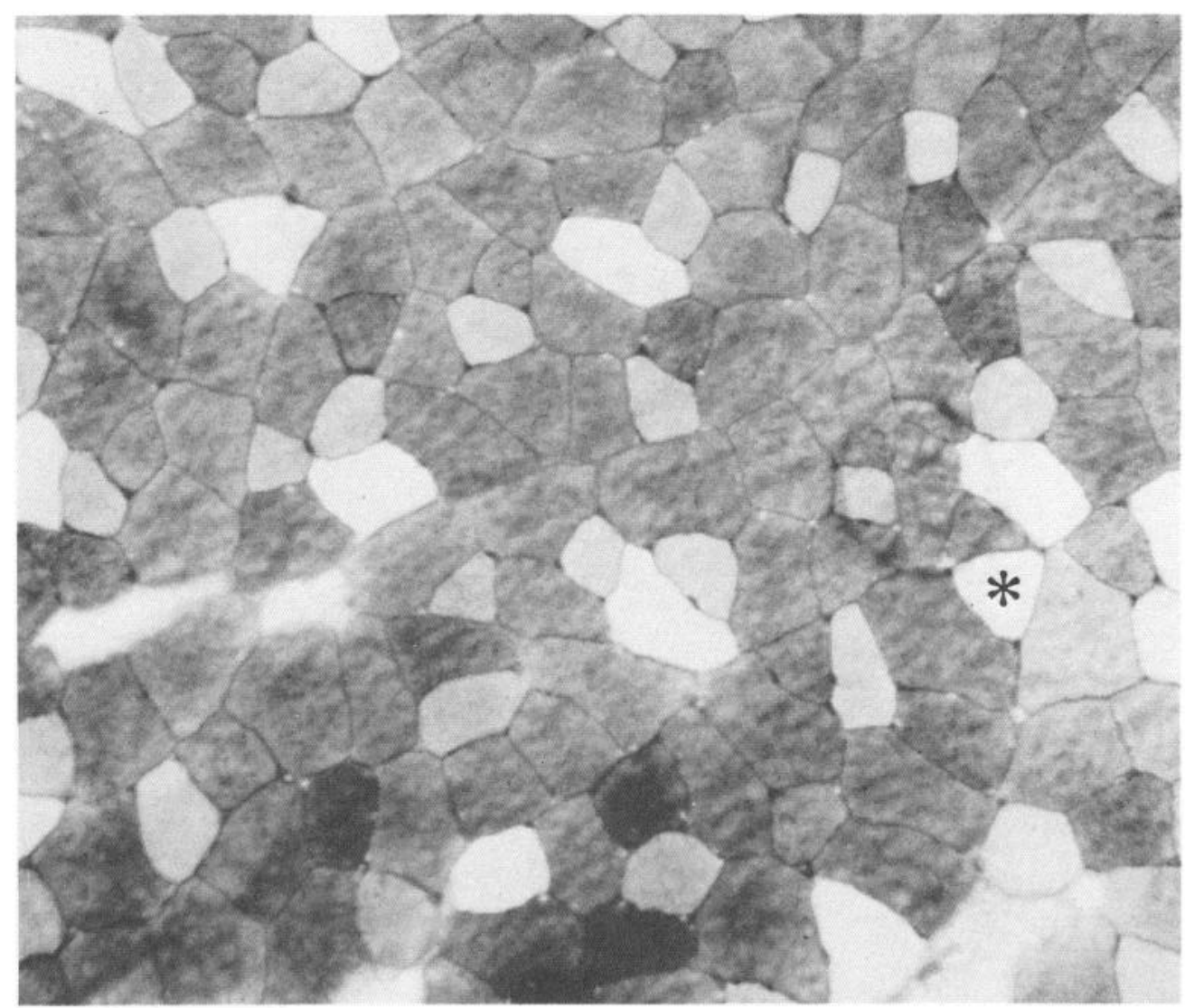

Figure 1. Cross section from a cat tibialis posterior muscle stained with the periodic acid Schiff reagent for glycogen. A single fast-oxidative type motor unit was electrically activated to deplete its glycogen stores. DG was administered during the final $15 \mathrm{~min}$ of activation. Depleted fibers were analyzed for DG6P, and the results are given in Table 2. Asterisk indicates a fiber with a biochemical profile different from the other depleted fibers. terminated by heating for $5 \mathrm{~min}$ in a $95^{\circ} \mathrm{C}$ water bath. The final measurement was made by adding $1 \mathrm{ml}$ of an indicator reagent consisting of $50 \mathrm{~mm}$ imidazole- $\mathrm{HCl}$ buffer, $\mathrm{pH} 7.0,30 \mathrm{~mm}$ ammonium acetate, 1 mм EDTA, $5 \mathrm{~mm} \mathrm{MgCl}_{2}, 5 \mathrm{~mm} \mathrm{NADP}{ }^{+}$, and $2 \mu \mathrm{g} / \mathrm{ml}$ of 6-phosphogluconate dehydrogenase. The NADPH product was measured after 15 $\min$ at $25^{\circ} \mathrm{C}$ on a filter fluorometer. Calculations were based on $1,2.5$, and $5 \mu \mathrm{M}$ DG6P standards carried through the entire procedure. Further details about the theoretical approach to the measurement of DG and DG6P have been recently published (Chi et al., 1987). Additional information about enzymatic cycling is also available (Chi et al., 1978; Lowry, 1980).

Glycogen. The glycogen assay was adapted from earlier reports (Lowry et al., 1977; Hintz et al., 1982). Fiber samples were preincubated in 1 $\mu \mathrm{l}$ of $0.04 \mathrm{~N} \mathrm{NaOH}$ for $30 \mathrm{~min}$ at $90^{\circ} \mathrm{C}$. The first reagent was added in a volume of $1 \mu \mathrm{l}$; it consisted of $100 \mathrm{~mm}$ acetate buffer, $\mathrm{pH} 4.0,0.04 \%$ BSA and $10 \mu \mathrm{g} / \mathrm{ml}$ amyloglucosidase from Aspergillus niger. After 30 min at $25^{\circ} \mathrm{C}$, a second reagent was added that contained $100 \mathrm{~mm}$ Tris, pH 8.1, $3 \mathrm{~mm} \mathrm{MgCl}_{2}, 900 \mu \mathrm{M}$ ATP, $1.5 \mathrm{~mm}$ 1, 4-dithiothreitol, $120 \mu \mathrm{M}$ $\mathrm{NADP}^{+}, 0.02 \% \mathrm{BSA}, 3 \mu \mathrm{g} / \mathrm{ml}$ hexokinase, and $1.5 \mu \mathrm{g} / \mathrm{ml} \mathrm{G} 6 \mathrm{PDH}$ from baker's yeast. The reaction was stopped with $2 \mu \mathrm{l}$ of $0.15 \mathrm{~N} \mathrm{NaOH}$ and heated $20 \mathrm{~min}$ at $80^{\circ} \mathrm{C}$ before cycling. The cycling reagent was the same as for DG6P except that the enzymes were reduced to $20 \mu \mathrm{g} / \mathrm{ml}$ glutamate dehydrogenase and $4 \mu \mathrm{g} / \mathrm{ml}$ baker's yeast G6PDH, which yielded about 2000 cycles. Standards were 3.5 and $7.0 \mu \mathrm{M}$ glycogen prepared in the preincubation solution. Further details of the analytic methods are provided by Lowry and Passonneau (1972).

\section{Results}

Fiber-type differences in control levels of glycogen and DG6P It is well known that fluctuations occur in muscle glycogen due to diurnal and dietary factors (Conlee et al., 1976). Therefore, it is a common procedure to enhance the storage of glycogen in muscles prior to experimentation with a dietary supplement of corn syrup (see Materials and Methods) in order to insure contrast between depleted and nondepleted fibers. Nevertheless, glycogen variations still appear from muscle to muscle. In the present study, values for whole-muscle glycogen content were $141-211 \mathrm{mmol} / \mathrm{kg}$ in 4 glycogen-loaded muscles. To see whether differences in fiber-type proportions among muscles might account for this variety and to establish single-fiber control values, glycogen was measured in single, PAS-positive (i.e., inactive) fibers that were classified into fiber types using enzymatic criteria.

Table 1 gives glycogen levels in 19 fibers, all in close proximity in a muscle fascicle and all exhibiting intense PAS staining. The fibers were classified as slow, fast-oxidative, and fast-glycolytic based on the activities of 3 energy-generating enzymes (Lowry et al., 1978). Slow- and fast-type fibers can be distinguished by adenylokinase and lactate dehydrogenase activities, while fastoxidative and fast-glycolytic type fibers can be separated by malate dehydrogenase activity. The average glycogen concentrations of slow fibers was $19 \%$ lower than that of fast-oxidative fibers, which was in turn $17 \%$ lower than that of fast-glycolytic fibers. However, these differences, in combination with the differences in fiber-type proportions (Ariano et al., 1973; McDonagh et al., 1980) are not sufficient to explain the wholemuscle variations. Although there were clear differences in average glycogen levels among the fiber groups, there was a margin of overlap between the slow and fast fibers, which indicates it would be difficult to classify fibers solely on the basis of glycogen content.

Baseline levels of DG6P were obtained since it would be expected that normal cell metabolism would elicit the uptake of a certain amount of the available DG. Although there was an overlap in the range of DG6P concentration for different fiber types, the slow fibers contained greater levels of DG6P 
Table 2. Biochemical characterization of individual fibers of a selectively activated single-motor unit (type FG)

\begin{tabular}{|c|c|c|c|c|c|}
\hline & \multirow[b]{2}{*}{ Glycogen } & \multirow[b]{2}{*}{ DG6P } & \multicolumn{3}{|c|}{ Type determinant enzymes } \\
\hline & & & $\begin{array}{l}\text { Lactate } \\
\text { dehydrogenase }\end{array}$ & $\begin{array}{l}\text { Adenylo- } \\
\text { kinase }\end{array}$ & $\begin{array}{l}\beta \text {-Hydroxyacyl } \\
\text { CoA } \\
\text { dehydrogenase }\end{array}$ \\
\hline \multicolumn{6}{|c|}{ Depleted fibers (FG) } \\
\hline 1 & 5 & - & 150 & 120 & 1.81 \\
\hline 2 & 6 & 79 & 174 & 126 & 1.98 \\
\hline 3 & 9 & 74 & 179 & 125 & 1.99 \\
\hline 4 & -3 & 80 & 175 & 130 & 1.91 \\
\hline 5 & 10 & - & 185 & 138 & 2.00 \\
\hline 6 & 7 & 81 & 172 & 111 & 1.86 \\
\hline 7 & 2 & - & 181 & 127 & 1.76 \\
\hline 8 & -1 & 82 & 179 & 118 & 1.74 \\
\hline 9 & -2 & 71 & 178 & 125 & 1.83 \\
\hline 10 & -3 & - & 157 & 120 & 1.61 \\
\hline 11 & 5 & - & 195 & 137 & 1.87 \\
\hline 12 & -1 & 76 & 188 & 126 & 1.67 \\
\hline Mean \pm SD & $4.5 \pm 0.30$ & $77.6 \pm 4.0$ & $176 \pm 12$ & $125 \pm 8$ & $1.84 \pm 0.12$ \\
\hline \multicolumn{6}{|l|}{ Depleted fiber } \\
\hline \multicolumn{6}{|c|}{ Nondepleted fibers (all types) } \\
\hline Mean $\pm S D$ & $141 \pm 24$ & $4 \pm 1$ & $215 \pm 104$ & $175 \pm 78$ & $4.7 \pm 4.0$ \\
\hline Range & $96-183$ & $2-6$ & $31-312$ & $33-246$ & $1.3-10.0$ \\
\hline
\end{tabular}

Glycogen and DG6P concentrations are expressed in $\mathrm{mmol} / \mathrm{kg}$; enzyme activities are in $\mathrm{mol} / \mathrm{kg} / \mathrm{hr}$. Glycogen and DG6P were measured in nondepleted fibers randomly selected from the muscle containing the activated motor unit. However, the range of enzyme activities in nondepleted fibers were taken from data previously obtained on cat motor units of the 3 major types (Nemeth et al., 1986). Some of the depleted motor unit fibers are shown in Figure 1. The asterisk in Figure 1 indicates the depleted type SO fiber.

than fast-oxidative or fast-glycolytic fibers. Thus, on average, the more tonically active slow fibers incorporated more DG.

\section{Glycogen concentration in $P A S$-positive and PAS-negative fibers}

The fibers of a motor unit activated through its motor axon are typically recognized in cross section by a relatively subjective assessment of PAS-negative fibers. A key determinant in this identification is the arrangement of depleted fibers in a wide mosaic pattern, as seen in Figure 1, rather than in an aggregated tight cluster.

Results of quantitative assays on 12 fibers of a single motor unit identified by glycogen depletion are given in Table 2 . The levels of 3 energy-related enzymes measured on the same fibers were uniform, which is consistent with our earlier findings (Nemeth et al., 1981, 1986). The glycogen levels averaged $4.5 \mathrm{mmol} /$ $\mathrm{kg}$, which is only $3.2 \%$ of the average control value (nondepleted PAS-positive fibers). The highest level of glycogen measured in a.fiber of the depleted motor unit was only $6 \%$ of control. Thus, the qualitative determination of glycogen content by PAS staining was substantiated by the quantitative glycogen measurement.

\section{DG6P levels in motor unit fibers}

Table 2 also gives the DG6P values for the PAS-negative fibers marked in Figure 1, subjectively judged to belong to the test motor unit. Except for one value, all DG6P values ranged from 71 to $82 \mathrm{mmol} / \mathrm{kg}$, nearly 20 times highcr than randomly selected nondepleted fibers of the same muscle. The exceptional depleted fiber (marked with an asterisk in Fig. 2) did not have an elevated DG6P level. This suggests that the fiber was not associated with the selectively activated motor unit, whose physiological characteristics were of the fast-twitch, fast-fatigable type. Moreover, the response of this aberrant fiber to the myosin ATPase stain and the activities for type-determinant enzymes differed from those fibers with elevated DG6P. The motor-unit fibers were classified as type IIb by myosin ATPase (Brooke and Kaiser, 1970) and FG by enzymatic typing (Lowry et al., 1978), while the aberrant fiber was type I or SO. We have observed fibers of a dissimilar type within an otherwise homogeneous fibcr-typc group of motor unit fibers in 2 or 3 out of approximately 200 fibers from 10 motor units. Spurious isolated PASdepleted fibers have also been found in essentially every control muscle we have examined. Thus, the accumulation of DG6P can be used to verify acute muscle-fiber activity and may provide a basis for the elimination of aberrantly glycogen-depleted fibers from consideration as part of a test motor unit.

\section{Association between PAS, glycogen, and DG6P}

In order to further test the reliability of DG6P to discriminate between activation- and nonactivation-induced glycogen depletion, 2 muscles were investigated which had abnormal motorunit fiber distributions based on glycogen depletion patterns. Both of these muscles had large regions of adjacent fibers staining weakly for PAS. This situation occurs in approximately onethird of our motor-unit experiments. One of the PAS-poor areas is shown in Figure 2. Glycogen and DG6P concentrations for 18 fibers selected from this area, along with subjective estimates 


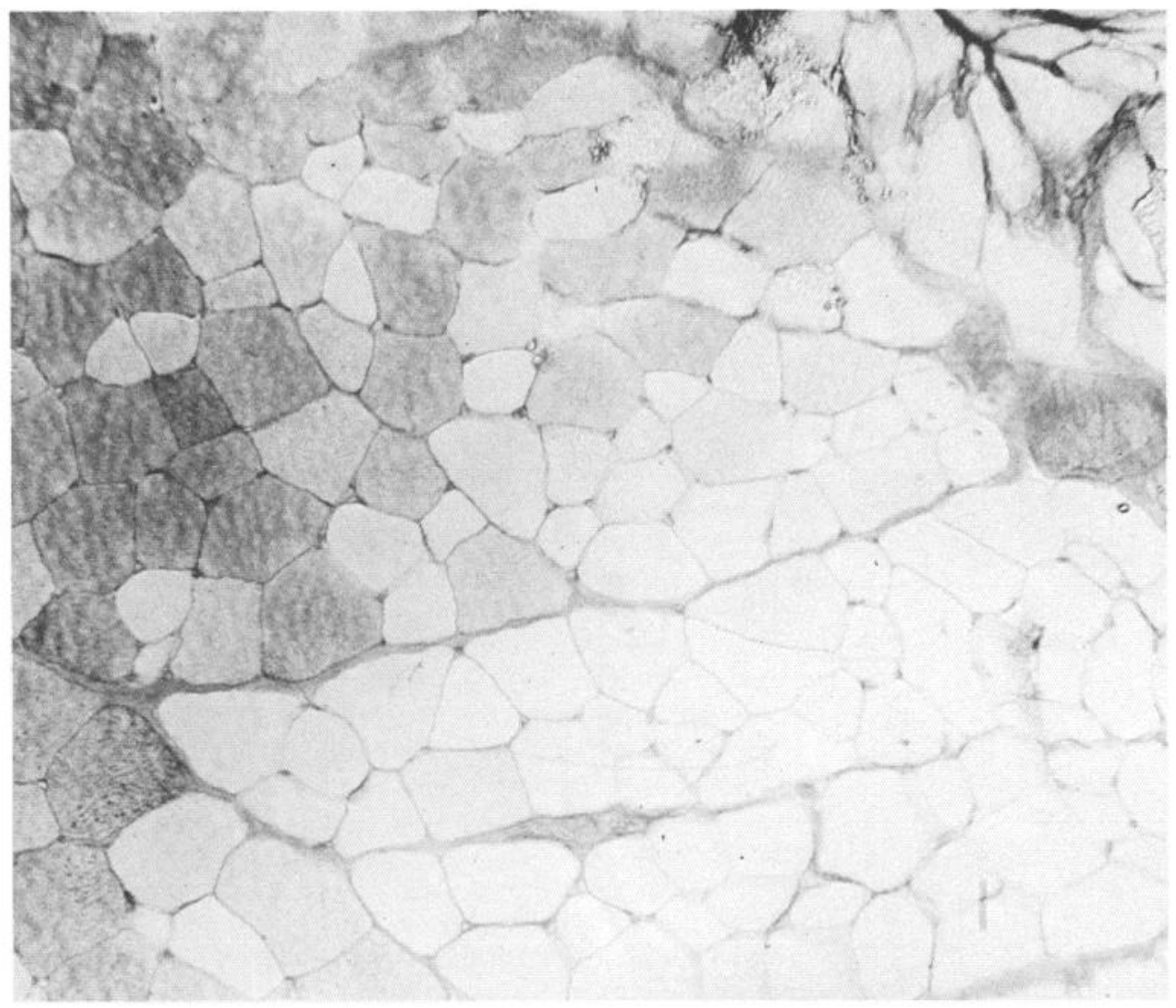

Figure 2. Another cross section from the same muscle in Figure 1 showing a wide area of depleted and partially depleted fibers, presumably as a result of ischemia. Results of DG6P analyses are given in Table 3. of the staining density (negative, intermediate, positive) for each fiber relative to others in this region, are given in Table 3 . The glycogen levels in all fibers of this PAS-poor-staining region were lower than those in normal PAS-positive areas (see Tables 1 and 2). The Table 3 glycogen values covered a large range but were generally much higher than might be predicted from the corresponding histochemical stain. In a similar area of another muscle, the range for glycogen was $38-90 \mathrm{mmol} / \mathrm{kg}$ (average, $70)$. In both muscles, the correlation between glycogen content and subjective stain intensity was poor, with considerable overlap between the negative and intermediate group.

The levels of DG6P were not elevated in any of these fibers from the glycogen-low, presumably ischemic, regions, suggesting that the weak stain and partial depletion of glycogen was not due to the selective motor-axon activation procedure. Finally, the area shown in Figure 2 was located near the area depicted in Figure 1, in which an activated motor unit had elevated DG6P (Table 2), thereby indicating that DG was available in the systemic circulation.

In summary, Figure 3 shows the association between levels of glycogen and DG6P concentrations in single muscle fibers under the 3 experimental conditions. In Figure $3 A$, nonactivated fibers of a glycogen-loaded control muscle show type-discriminant levels of glycogen and separation of fast- from some slowtype fibers by basal levels of DG uptake. In Figure $3 B$, nonactivated fibers from a presumably ischemic region of muscle with poor PAS staining have a range of glycogen beginning 4 times higher than the highest glycogen-depleted fibers of the motor unit (Fig. $3 C$ ) but not reaching the average of other glycogenloaded muscles. DG6P was not elevated above basal levels. In Figure $3 C$, fibers of a selectively activated motor unit have 30 times lower glycogen levels and 20 times higher DG6P levels than nonactivated control fibers from the same muscle. An aberrantly depleted fiber has 28 -fold lower glycogen level than control but a DG6P level equal to that of controls.

\section{Discussion}

The autoradiographic 2-deoxy-D- $\left[{ }^{14} \mathrm{C}\right]$ glucose $\left({ }^{14} \mathrm{C}-\mathrm{DG}\right)$ method originally developed by Sokoloff et al. (1977) to measure regional cerebral glucose utilization is now a widely used tool. In principle, the ${ }^{14} \mathrm{C}$-DG competes with glucose for transport into cells by a common carrier system and for intracellular phosphorylation by hexokinase. Unlike glucose 6-phosphate, ${ }^{14} \mathrm{C}$-DG6P cannot be metabolized further to an analog of fructose-6-phosphate and is trapped inside the cells. Thus, ${ }^{14} \mathrm{C}$-accumulation, which is detectable by autoradiography, provides a measure of glucose consumption. This technique has been employed as a marker for glucose metabolism in whole muscle (Rapoport et al., 1978) and in individual fibers of single motor units (Toop et al., 1982). Both reports demonstrated that muscle acutely activated by electrical stimulation can specifically take up the tracer. Furthermore, Toop et al. (1982) showed that all fiber types, irrespective of their rates of glycogen depletion or glucose utilization, can be labeled with ${ }^{14} \mathrm{C}$-DG. (It should be emphasized that glycogen consumption is not accompanied by DG6P production, since hexokinase is not involved.)

An important technical consideration is that the autoradiographic method requires a delay of $30-45 \mathrm{~min}$ after the ${ }^{14} \mathrm{C}-\mathrm{DG}$ administration for circulatory dissipation of the unmetabolized ${ }^{14} \mathrm{C}$-DG. A recent report from one of our laboratories describes an enzymatic method for measuring DG6P directly in brain tissue (Chi et al., 1987). Since the technique requires no time 
Table 3. Glycogen and 2-deoxyglucose-6-phosphate concentrations in glycogen-poor individual fibers

\begin{tabular}{|c|c|c|}
\hline PAS stain & Glycogen & DG6P \\
\hline \multicolumn{3}{|l|}{ Negative } \\
\hline 1 & 41 & 5.2 \\
\hline 2 & 96 & 7.0 \\
\hline 3 & 93 & 5.2 \\
\hline 4 & 53 & 4.6 \\
\hline 5 & 69 & 3.4 \\
\hline Mean $\pm S D$ & $70 \pm 24$ & $5.0 \pm 1.3$ \\
\hline \multicolumn{3}{|l|}{ Intermediate } \\
\hline 6 & 51 & 4.8 \\
\hline 7 & 96 & 5.4 \\
\hline 8 & 76 & 5.7 \\
\hline 9 & 79 & 7.9 \\
\hline 10 & 90 & 6.8 \\
\hline 11 & 87 & 4.7 \\
\hline 12 & 120 & 7.4 \\
\hline 13 & 50 & 5.0 \\
\hline 14 & 95 & 3.9 \\
\hline 15 & 87 & 4.0 \\
\hline Mean $\pm \mathbf{S D}$ & $83 \pm 21$ & $5.6 \pm 1.4$ \\
\hline \multicolumn{3}{|l|}{ Positive } \\
\hline 16 & 115 & 5.9 \\
\hline 17 & 105 & 3.3 \\
\hline 18 & 119 & 5.2 \\
\hline Mean $\pm \mathrm{SD}$ & $113 \pm 7$ & $4.8 \pm 1.3$ \\
\hline Overall average & $85 \pm 24$ & $5.3 \pm 1.3$ \\
\hline
\end{tabular}

All fibers were taken from the glycogen-poor region illustrated in Figure 2. Figures 1 and 2 were taken from separate regions of the same muscle. Therefore, the DG6P data in this table can be compared with that for nondepleted fibers in Table 2 . In another muscle with a similar glycogen-poor region, the range of glycogen values in the region was $38-90 \mathrm{mmol} / \mathrm{kg}$ (mean $=80$ ). In contrast, glycogen levels in nondepleted fibers ranged from 96-249 (mean $\pm S D=165 \pm 39$ ). Concentrations are expressed in $\mathrm{mmol} / \mathrm{kg}$.

delay, it is possible to measure changes in glucose consumption on a time scale of a few minutes or even less. The DG6P assay, made suitable for use on fragments of single fibers dissected from muscle cross sections, eliminates the problem of resolution (which usually limits autoradiographic methods) and permits precise identification of motor-unit fibers by detection of cellular activation. The prominent finding of this study is that levels of DG6P are elevated approximately 20 times by selective activation over nonactivated fibcrs of the same muscle.

This report also supports our earlier observation (Nemeth et al., 1986) that the glycogen-depletion method, while an invaluable tool for the identification of motor units, has limitations. Specifically, the PAS stain cannot discriminate between activation- and nonactivation-induced glycogen depletion. Areas with extensive depletions, such as that illustrated in Figure 2, can be a result of local ischemia, which is difficult to prevent in acute electrophysiological (motor-unit) experiments. In a study of the stability of contractile properties in rats, Segal and Faulkner (1985) calculated the critical radius for in vitro whole-muscle oxygen diffusion. They showed that the rates of glycogen depletion and hypoxia are parallel. Thus, neither glycogen (PAS) staining nor quantitative assays for glycogen content can reliably distinguish between glycogen depletion secondary to activation or factors such as ischemia (see Table 3).
In contrast to glycogen utilization, ischemia would be expected to elicit the uptake of less, rather than more, glucose as a consequence of reduced perfusion, not hypoxia per se (Randle and Smith, 1958; Morgan et al., 1961). This is confirmed by our results showing that DG6P was not elevated in fibers of the glycogen-depleted whole fascicle (Fig. 2, Table 3). Therefore, DG6 $\mathrm{P}$ is an independent indicator of fiber activation that may distinguish among fibers glycogen depleted as a result of activation and those depleted as a consequence of other factors (i.e., ischemia). For this reason, the DG6P test can justify the practice of excluding large areas of depleted fibers from the analysis of a glycogen-depleted motor unit.

The spurious depletion of glycogen from fibers is difficult to distinguish from activation-induced depletion. On several occasions we observed PAS-negative fibers in muscles from animals that had undergone preparative surgery for recording but had not received direct electrical stimulation of their nerve supply. Moreover, a depleted fiber that neither took up DG6P nor had similar ATPase-staining properties was found among selectively activated motor-unit fibers (Fig. 1, Table 2). Kugelberg (1973) reported a similar finding in 2 out of 340 fibers of glycogen-depleted motor units. Random depletions may be due to ongoing muscle remodeling via degeneration. It is very unlikely that a surgical irritation to the muscle or nerve would cause an isolated single-fiber depletion.

In summary of this issue, we present several lines of evidence to suggest that PAS staining may not always identify selectively activated muscle fibers: (1) Quantitative levels of glycogen varied among glucose-loaded muscle (Tables 1-3), and did not consistently vary with PAS-staining intensity (Fig. 2, Table 3); (2) fasciclcs of PAS-dcpleted fibers that were not experimentally stimulated did not show elevated levels of DG6P; (3) spurious isolated PAS-negative fibers occurred in nonstimulated control muscles; and (4) a single PAS-negative fiber without elevated DG6P, found among fibers of an activated motor unit with elevated DG6P, was determined to be a separate fiber type from the activated motor unit. Collectively these data support the use of DG6P as an independent marker for motor-unit activation. The data further suggest that rare fibers not of the appropriate histochemical type could be justifiably eliminated as part of the activated motor unit.

The time courses of glycogen and DG metabolism favor the DG6P verification of fibers in glycogen-depleted motor units. In our experience, several minutes of electrical, motor-axon activation are required for fatigue-sensitive fibers to become depleted of their glycogen and up to an hour for fatigue-resistant fibers. Depletion, therefore, requires a prolonged, selective activation. Repletion of glycogen is slow. Even with enhanced dietary intake of glucose, both fast and slow human muscle types take 1-2 d to return to full glycogen capacity after depletion (Piehl, 1974). Muscle fibers of rats are repleted far more quickly; oxidative muscle fibers take $2 \mathrm{hr}$, while glycolytic fibers take 24 hr (Terjung et al., 1974; Fell et al., 1980). Thus, depletions from activation other than that induced by the selective electrical stimulation of the motor axon may exist. However, an association with elevated DG6P is unlikely because of the difference in the time course of DG6P metabolism, as explained below.

DG6P records a glucose-utilizing event during a relatively brief time period. In rat brain, DG6P appears within seconds of a stimulus. The entrapment lasts for about $1 \mathrm{hr}$ before there is a decline. The induction of glucose uptake in muscle may take a little longer due to the high capacity for glycogenolysis 

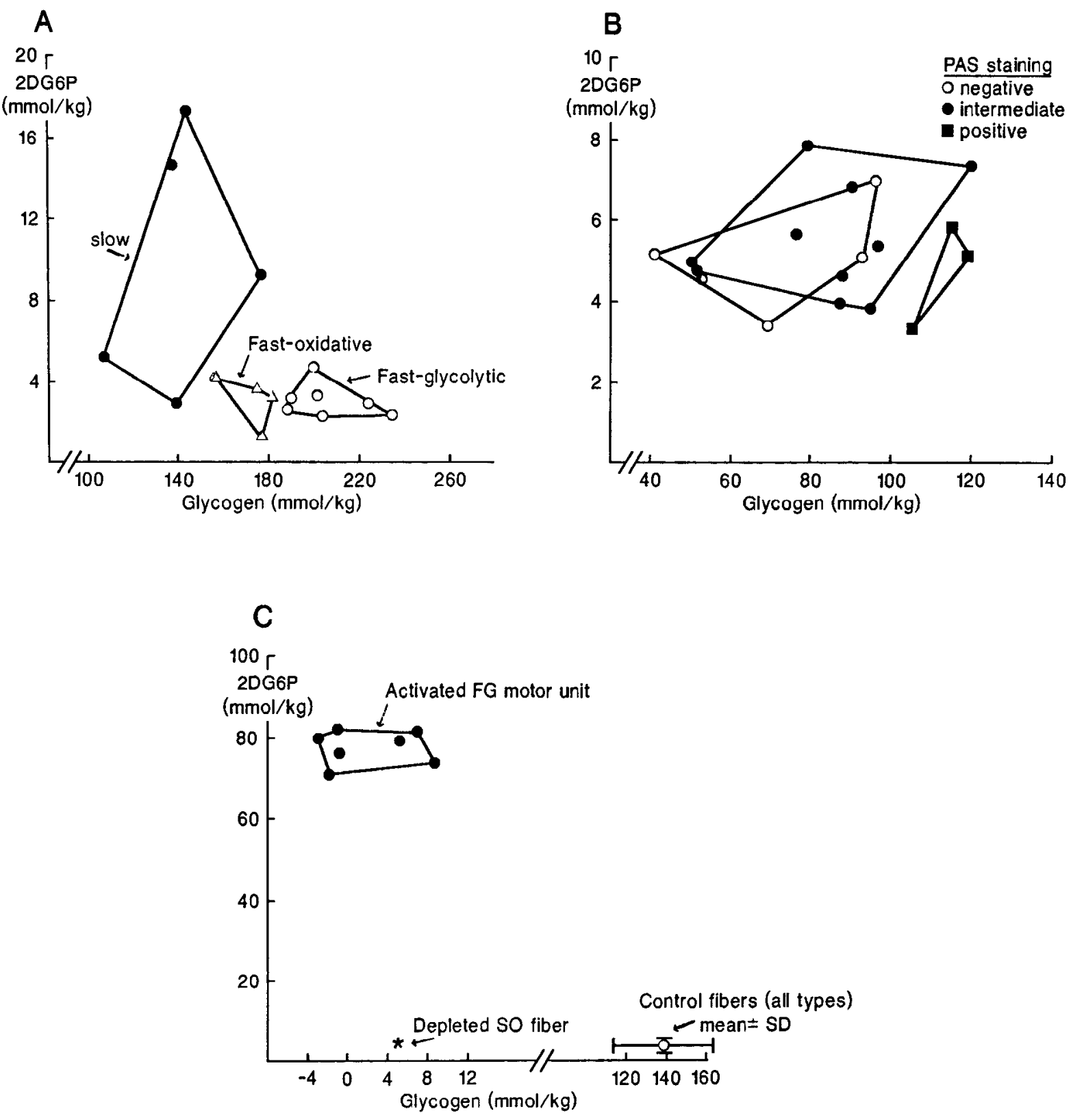

Figure 3. The association between glycogen and DG6P concentrations on the same individual fibers under 3 experimental conditions. $A$, Nonactivated control muscle fibers of the 3 major motor-unit types. $B$, Fibers from an apparently ischemic area of muscle, as shown in Figure 2 . $C$, Fibers of a selectively activated type FG motor unit (from Fig. 1 and Table 2 ) compared with aberrantly depleted SO fibers $\left({ }^{*}\right)$ from a different motor unit (see text) and control (nonactivated) fibers from the same muscle.

in some fiber types. Therefore, in the present study, DG was administered in the last few minutes of single motor-unit activation, at a time when the unit was nearing maximum fatigue and glycogen depletion. Highly oxidative fatigue-resistant fibers that have not completely exhausted their glycogen should, in particular, be easily discernible by enhanced DG6P levels. Because of the rapid appearance and disappearance of DG6P relative to glycogen metabolism, the method is an independent marker for immediate fiber activation by the specific electrical stimulus to the motor axon. The possibility that muscle cells could be inadvertently activated over a sufficiently prolonged period to be glycogen depleted with DG present is discounted because they would generate force and be detected during physiological tests. In contrast, if activation had occurred before the physiological measurements began, there would be no DG available for phosphorylation.

Motor units consist of biochemically identical fibers among a heterogeneous whole-muscle fiber population (Burke et al., 1971; Nemeth et al., 1981, 1986). Therefore, a single fiber should be sufficient to represent the unit for determination of its biochemical characteristics. This assumption is valid only if the fiber identification is absolutely certain. The DG6P method increases the certainty of making a correct determination and thereby facilitates the biochemical study of motor units by reducing the number of single-fiber measurements for significant results and comparisons.

In addition to its advantages in motor-unit studies, the sensitivity of the DG6P assay coupled with the in situ identification 
of muscle cells should make it possible to quantify glucose utilization in fibers of specific phenotypes. Specificity of the assay is established by our demonstration that the more tonically active slow fibers take up more glucose than fast fibers during normal cellular maintenance. Thus, the method has the potential for providing important new information, as diverse as quantitating muscle activity as an epigenetic factor in trophic events, and correlating dynamic aspects of muscle glucose metabolism with energy-related enzyme capacity and contractile function.

\section{References}

Ariano, M. A., R. B. Armstrong, and V. R. Edgerton (1973) Hindlimb muscle fiber populations of five mammals. J. Histochem. Cytochem. 21: 51-55.

Brooke, M. S., and K. K. Kaiser (1970) Three myosin adenosine triphosphate systems: The nature of their $\mathrm{pH}$ lability and sulfhydryl dependence. J. Histochem. Cytochem. 18:670-672.

Burke, R. E. (1981) Motor units: Anatomy, physiology, and functional organization. In Handbook of Physiology, Vol. 2, The Nervous System: Motor Control, Pt. 1, B. Brooks, ed., pp. 345-422, American Physiological Society, Bethesda, MD.

Burke, R. E., D. N. Levine, F. E. Zajac, P. Tsairis, and W. K. Engel (1971) Mammalian motor units: Physiological-histochemical correlation in thrce types in cat gastrocncmius. Scicncc 174: 709-712.

Chi, M. M.-Y., C. V. Lowry, and O. H. Lowry (1978) An improved enzymatic cycle for nicotinamide-adenine dinucleotide phosphate. Anal. Biochem. 89: 119-129.

Chi, M. M.-Y., M. E. Pusateri, J. G. Carter, B. J. Norris, D. B. McDougal, and O. H. Lowry (1987) Enzymatic assays for 2-deoxyglucose and 2-deoxyglucose-6-phosphate. Anal. Biochem. 161:508-513.

Conlee, R. K., M. J. Rennie, and W. W. Winder (1976) Skeletal muscle glycogen content: Diurnal variation and effects of fasting. Am. J. Physiol. 231: 614-618.

Edström, L., and E. Kugelberg (1968) Histochemical composition, distribution of fibers and fatigability of single motor units. J. Neurol. Neurosurg. Psychiatry 31: 424-433.

Fell, R. D., J. A. McLane, W. W. Winder, and J. O. Holloszy (1980) Preferential resynthesis of muscle glycogen in fasting rats after exhausting exercises. Am. J. Physiol. (Regulatory Integrative Comp. Physiol. 7) 238: R328-R332.

Gordon, D. A., R. M. Enoka, D. G. Stuart, B. J. Norris, P. M. Nemeth, and O. H. Lowry (1987) Activation of single muscle fibers revealed by 2-deoxyglucose-6-phosphate. Soc. Neurosci. Abstr. 13(2): 1217.

Hamm, T. M., P. M. Nemeth, L. Solanki, D. A. Gordon, R. M. Reinking, and D. G. Stuart (1987) Association between biochemical and physiological properties in single motor units. Muscle Nerve 11:95-104.

Hintz, C. S., M. M.-Y. Chi, R. D. Fell, J. L. Ivy, K. K. Kaiser, C. V. Lowry, and O. H. Lowry (1982) Metabolic changes in individual rat muscle fibers during stimulation. Am. J. Physiol. (Cell Physiol. 11) 242: $\mathrm{C} 218-\mathrm{C} 228$.

Krnjevic, K., and R. Miledi (1958) Motor units in the rat diaphragm. J. Physiol. (Lond.) 140: 427-439.

Kugelberg, E. (1973) Histochemical composition, contraction speed and fatigability of rats soleus motor units. J. Neurol. Sci. 20: 177198.

Lowry, C. V., J. S. Kimmey, S. Felder, M. M.-Y. Chi, K. K. Kaiser, P. N. Passonneau, K. A. Kirk, and O. H. Lowry (1978) Enzyme patterns in single human muscle fibers. J. Biol. Chem. 253: 8269-8277.

Lowry, O. H. (1980) Amplification by enzymatic cycling. Mol. Cell. Biochem. 32: 135-146.

Lowry, O. H., and J. V. Passonneau (1972) A Flexible System of Enzymatic Analysis, Academic, New York.

Lowry, O. H., S. J. Berger, M. M.-Y. Chi, J. G. Carter, A. Blackshaw, and W. Outlaw (1977) Diversity of metabolic patterns in human brain tumors -1 . High energy phosphate compounds and basic composition. J. Neurochem. 29: 959-977.

McDermott, J. C., G. C. B. Elder, and A. Bonen (1987) Adrenal hormones enhance glycogenolysis in nonexercising muscle during exercise. J. Appl. Physiol. 63: 1275-1283.

McDonagh, J. C., M. D. Binder, R. M. Reinking, and D. G. Stuart (1980) Tetrapartite classification of the motor units of cat tibialis posterior. J. Neurophysiol. 43: 621-629.

Morgan, H. E., M. J. Henderson, D. N. Reger, and C. R. Park (1961) Regulation of glucose uptake. I. The effect of insulin and anoxia on glucose transport and phosphorylation in the isolated perfused heart of normal rats. J. Biol. Chem. 236: 253-261.

Nemeth, P. M., D. Pette, and G. Vrbová (1981) Comparison of enzyme activities among single muscle fibers within defined motor units. J. Physiol. (Lond.) 311: 489-495.

Nemeth, P. M., L. Solanki, D. A. Gordon, T. M. Hamm, D. M. Reinking, and D. G. Stuart (1986) Uniformity of metabolic enzymes within individual motor units. J. Neurosci. 6: 892-898.

Piehl, K. (1974) Time course for refilling of glycogen stores in human muscle fibres following exercise-induced glycogen depletion. Acta Physiol. Scand. 90: 297-302.

Randle, P. J., and G. H. Smith (1958) Regulation of glucose uptake by muscle. 1 . The effects of insulin anaerobosis and cell poisons on the uptake of glucose and release of potassium by isolated rat diaphragm. Biochem. J. 70: 490-500.

Rapoport, S. I., K. Ohno, and W. J. Schwartz (1978) Activity-related regional uptake of $\left[\mathrm{C}^{14}\right]$ deoxyglucose by rat quadriceps femoris muscle. Fxp. Neurol. 60: 168-174.

Segal, S. S., and J. J. Faulkner (1985) Temperature-dependent physiological stability of rat skeletal muscle in vitro. Am. J. Physiol. (Cell Physiol. 17) 248: C265-C270.

Sokoloff, L., M. Reivich, C. Kennedy, M. H. DesRosiers, C. S. Patlak, K. D. Pettigrew, O. Sakurade, and M. Shinohara (1977) The $\left[{ }^{14} \mathrm{C}\right]$ deoxyglucose method for the measurement of local cerebral glucose utilization: Theory, procedure, and normal values in the conscious and anesthetized albino rat. J. Neurochem. 28: 897-916.

Terjung, R. L., K. M. Baldwin, W. W. Winder, and J. O. Holloszy (1974) Glycogen repletion in different types of muscle and in liver after exhausting exercise. Am. J. Physiol. 226: 1387-1391.

Toop, J., R. E. Burke, R. P. Dum, M. J. O'Donovan, and C. B. Smith (1982) 2-Deoxyglucose autoradiography of single motor units: Labeling of individual acutely active muscle fibers. J. Neurosci. Methods 5: 283-289.

Vrbová, G., T. Gordon, and R. Jones (1978) Nerve-Muscle Interaction, pp. 53-118, 166-181, Chapman and Hall, London. 